\title{
Capturing focused attention
}

\author{
GABRIEL NEO and FOOK K. CHUA \\ National University of Singapore, Singapore
}

\begin{abstract}
When attention is diffuse, as in a visual search task, an abrupt onset almost invariably succeeds in capturing attention. But if attention had been cued in advance to a different location, the same onset may then fail to capture attention (Theeuwes, 1991; Yantis \& Jonides, 1990). In previous demonstrations, the onset appeared frequently. This may have diminished the onset's novelty, which in turn could have affected its potency in capturing attention. The question we asked was whether preserving the onset's novelty could enhance its capacity in capturing attention, even when attention had been prioritized elsewhere. As in Theeuwes's (1991) study, observers were cued to the target location with a 100\%-predictive central arrow cue. The frequency with which visual transients were introduced was varied across experiments. When the onset stimulus appeared frequently (Experiment 1), it indeed failed to capture attention. But when its appearance was relatively infrequent (Experiment 2), capture effects were clearly observed. In Experiment 3, the target appeared in one location throughout the experiment. This would have improved target localization, but an infrequently appearing onset stimulus still successfully captured attention.
\end{abstract}

The theoretical distinction between voluntary and involuntary attentional control has long been made (see, e.g., James, 1890). The consensus appears to be that in most situations, attentional control is the result of a complex interaction between bottom-up involuntary (exogenous) and top-down voluntary (endogenous) control (see, e.g., Klein \& Shore, 2000; Pashler, Johnston, \& Ruthruff, 2001; Yantis, 1998, 2000). However, one issue remains controversial: whether attentional control can be purely stimulus driven.

Theeuwes $(1992,1995)$ stressed the view that at the early, preattentive phase, attentional selectivity is strictly bottom-up, with control dictated ("captured") by the most salient element in the visual field - for instance, by an item that has a unique property. In contrast, Folk and his colleagues (Folk \& Remington, 1998, 1999; Folk, Remington, \& Johnston, 1992) argued that an object's capacity to control attention is contingent upon the observer's goals. To the extent that the goal specifications also encompass the properties of the salient object, the object would indeed succeed in capturing attention. The same object, however, would fail to capture attention if these salient features were not task relevant. The observation made by James (1890) exemplifies the contingent-capture view: "A faint tap per se is not an interesting sound; it may well escape being discriminated from the general rumor of

This research was supported by Grant R-581-000-042-112 from the National University of Singapore. Portions of this work were presented at the 28th Annual Meeting of the European Conference on Visual Perception in A Coruña, Spain. Data for Experiment 2 were gathered by G.N. as part of his honors thesis. Correspondence concerning this article should be addressed to F. K. Chua, Department of Psychology, National University of Singapore, Kent Ridge Crescent, Singapore 119260 (e-mail: fkchua@leonis.nus.edu.sg). the world. But when it is a signal, as that of a lover on the windowpane, it will hardly go unperceived" (p. 418).

This debate pertains to the situation in which attention is diffuse, with control yet to be allocated to any particular object or location. But, when attention has been deployed in advance to a specific location ("prioritized"; Yantis \& Johnson, 1990), there appears to be a consensus that a distractor appearing elsewhere is unlikely to control attention exogenously. Thus, although an onset object may have the unique capacity to capture attention in a diffuse situation (Yantis \& Jonides, 1984), the same onset will fail if attention has been oriented elsewhere by a $100 \%$-valid central cue (Yantis \& Jonides, 1990). Yantis and Jonides (1990) concluded that onsets do not automatically capture attention.

The experimental paradigm of Yantis and Jonides (1990) allowed a stringent test of the intentionality criterion of automaticity (LaBerge, 1981; Logan, 1981; Neumann, 1984; Posner, 1978). This involved using a central cue to achieve advance orienting to the location in which the target was guaranteed to appear. In their Experiment 2, the critical contrast was between presenting the target as either an onset or a no-onset object. ${ }^{1}$ In the event that the target was not an onset object, a distractor appeared as an onset. They examined whether this onset distractor could capture attention when attention had been oriented elsewhere. Their results showed that when the central cue preceded the target (i.e., when observers had time to focus their attention on the target location), there was no difference in reaction times (RTs) between the onset and no-onset target conditions, implying that the onset distractor failed to capture attention. But when the central cue appeared simultaneously with (or after) the target, RTs were reliably longer for the no-onset target. That is, when attention was in a diffuse state, the same onset distractor now successfully 
controlled attention. Thus, their data suggest that onsets do not attract attention automatically, and they concluded that the intentionality criterion was not fulfilled.

To explain the contrast in the onset's effectiveness in controlling attention in the diffuse and focused states, Yantis and Johnson (1990) proposed an attentional priority hypothesis. Their claim was that when multiple objects vie for attentional control, top-down considerations determine how attention gets prioritized. When attentional control is endogenous, the cued location is accorded the highest priority, with resources allocated there first. Once this priority has been set, no stimulus, not even one that appears as an abrupt onset, can jump the attentional priority queue, as it were, and seize attentional control. Instead, the onset stimulus is placed at the end of the queue, with control passing to it only after items preceding it in the queue have been serviced. However, if attention has yet to be prioritized (i.e., if attention is diffuse), that same onset stimulus now is assigned the highest priority, and attentional control passes immediately to it: The onset captures attention. The Yantis and Jonides (1990) results exemplify this idea.

Recall that in the Yantis and Jonides (1990) experiment, the onset distractor appeared when the target was revealed by the offset of several line segments making up the placeholder. Theeuwes (1991) raised the point that in this setup, two sets of visual transients were simultaneously introduced: one set at the target location, produced by the offset of line segments, and the other at the site of the onset. The potency of the onset transients may have been undermined by competition from the offset transients. In Theeuwes's (1991) experiment, visual transients were introduced one set at a time. As in Yantis and Jonides (1990), observers were oriented in advance to the target location by a central cue. In the critical conditions, an onset was introduced before the target was revealed but after attention had, presumably, been deployed at the target location. Theeuwes's (1991) results showed that even under these conditions, the onset failed to capture attention.

In Theeuwes's (1991) experiments, the onset stimulus appeared on $80 \%$ of the trials, and the frequent appearance of the onset could have had a bearing on his results. One of the insights of the orienting response (OR) literature is that eliciting an OR depends on the stimulus's novelty. According to Sokolov (1975), repeated exposure to an (unchanging) visual scene establishes for the observer a neuronal model, which may be regarded as the cortical representation of the prevailing stimulation. The neuronal model thus embodies the specific expectancies of the observer. So long as the environment remains invariant, the incoming visual information should match the neuronal model. This match suppresses (exogenous) orienting. But when the environment changes (e.g., a novel stimulus appears suddenly), the cortical representation, which includes the stimulation from this new stimulus, now fails to match the neuronal model. This mismatch disinhibits the orienting centers, triggering an OR to the novel stimulus.

Thus, the OR may be seen as a manifestation of exogenous control. When the OR is elicited, sense receptors are oriented immediately toward the locus of the change to discover its aspects. The initial sensory analysis probably determines the nature of the processing that might follow. Repeated presentation of the novel stimulus will eventually lead to the incorporation of its stimulation pattern into the neuronal model. When that happens, habituation occurs, and no OR is then triggered when the stimulus appears.

The question we asked was whether repeatedly presenting the onset stimulus as in Theeuwes (1991), which probably would have diminished its novelty, compromised its attention-capturing capacities. An onset that appears frequently ought soon to become part of the observer's expectations of how the events in a trial unfold. Observers who expect an onset, then find these expectations fulfilled, are unlikely to have their attention attracted to the location of the onset transients.

A related line of evidence showed that with practice, observers were able to evade capture by an onset. Warner, Juola, and Koshino (1990) showed that the potency of a peripheral onset cue in capturing attention diminished as their observers became more practiced. In one condition, their observers had to attend to the location (which was $80 \%$ valid) opposite where the cue abruptly appeared. Their results showed that initially this peripheral cue captured attention: Their observers were not able to shift their attention immediately to the location opposite where the onset had appeared. Because their attention was detained at the onset's location, RTs were shorter when the target appeared near than when it appeared opposite the peripheral cue. However, with more practice, the observers were able to shift their attention swiftly to the location opposite the onset, and their RTs then became longer when the target appeared near the onset. Kim and Cave (1999, Experiment 2) reported quite similar practice effects with a color (distractor) singleton; after the first block, the color singleton failed to capture attention.

Both the Warner et al. (1990) and Kim and Cave (1999) studies examined the case in which attention was diffuse. The crucial point about practice effects is that initially, top-down control has yet to be precisely tuned, and attention could not be guided efficiently to the target location. Thus, an onset or a color singleton succeeds in capturing attention. Practice tunes top-down control, however, allowing swift attentional deployment to the target location. Once this has been achieved, attentional capture could be evaded. We note, however, that the issue of practice improving top-down control is much less of an issue (or, indeed, not an issue at all) when attention has been precued to the location where the target is guaranteed to appear. We engaged with this issue in our Experiment 3.

\section{Overview of Experiments}

The main variable was the frequency of onset appearance, which was varied across experiments. Experiment 1 was designed to replicate Theeuwes (1991), but with a slightly reduced frequency of onset $(75 \%$, vs. $80 \%$ in Theeuwes's experiment). The critical experiment was Experiment 2 , in which the onset frequency was reduced to 
less than 20\%. In Experiment 3, a more stringent test of the intentionality criterion was implemented in which the target appeared in one location throughout the experiment.

The experiments were modeled on Theeuwes (1991). The targets and distractors were initially camouflaged with additional line segments in the form of digit-8 "placeholders" (Todd \& Van Gelder, 1979). The display consisted of four placeholders arranged around the circumference of an imaginary circle so they were equidistant from each other. The $100 \%$-valid central cue was an arrow pointing toward the target location. The sequence of events for the focused-attention trials is depicted in panels A-E of Figure 1. Following the appearance of the fixation symbol (Figure 1A), the placeholders were ramped on (Figure 1B), achieving their final luminance of $30 \mathrm{~cd} / \mathrm{m}^{2}$ after $1 \mathrm{sec}$. The arrow cue was then ramped on (Figure 1C), achieving the same final luminance after 1 sec (Figure 1D1). The baseline condition was one in which no visual transients appeared during the trial. The placeholders shed line segments so they were transformed into letters $600 \mathrm{msec}$ later (Figure 1E1). Three placeholders were transformed into distractor letters, one each of $S, U$, and $P$. The placeholder toward which the arrow pointed turned into one of two possible targets, an $E$ or an $H$. The observers had to identify this letter by striking one of two prespecified keys. The main dependent variable was response latency.

The critical comparison was between the baseline condition and two types of trials in which visual transients were introduced before the target was revealed: (1) In the form change condition (Figure 1D2), several line segments disappeared from one of the distractor placeholders, revealing a distractor letter. (2) In the onset condition, the form change was accompanied by the sudden appearance of four spots in the corners of an imaginary rectangle that bounded the distractor letter (Figure 1D3). The target displays in the form change and onset conditions are depicted in Figures 1E1 and 1E2, respectively. The display remained until the observer responded. For both the form change and onset conditions, a central arrow cue preceded the appearance of the visual transients by at least $400 \mathrm{msec}^{2}$ Attention should have been deployed successfully at the target site by the time the transients materialized.

An issue of interest is the time course of top-down modulation of stimulus capture. In several recent reports (e.g., Kim \& Cave, 1999; Theeuwes, Atchley, \& Kramer, 2000), capture effects were found to be very brief indeed. To examine the temporal profile of this top-down modulation, we contrasted conditions in which we introduced the form change or onset either 60 or $200 \mathrm{msec}$ before the target was revealed.

In our experiments, the onset object was made as different as possible from the target. The onset comprised four spots that contained no straight-line features; when they appeared, it was as an abrupt onset. The target letter, on the other hand, contained only straight lines and was revealed when line segments camouflaging it disappeared from the placeholder (i.e., it was accompanied by offset transients). In addition, unlike in Theeuwes (1991), the onset spots never appeared at or near the target location. One might argue that under these conditions, capture might fail even in the most congenial of circumstances - when attention was diffuse. To examine the efficacy of the onset spots as a capture stimulus, the case in which the target was not precued was also examined. In this condition, the sequence proceeded in the manner depicted in Figure 1, except that the arrow cue was invisible for Figures 1A-1D, appearing only when the target and the other distractors were revealed (Figure 1E). We refer to this as the simultaneous condition. For the onset trials, four spots surrounding a distractor letter appeared simultaneously with the arrow cue pointing toward the target (Figure 1E2). These were contrasted to no-onset trials, which were identical in all respects except that the onset spots were absent when the target and distractors were revealed (Figure 1E1).

\section{EXPERIMENT 1}

In Experiment 1, the onset stimulus appeared on $75 \%$ of the trials. In the critical trials, a 100\%-valid central arrow cue appeared $400 \mathrm{msec}$ before visual transients were introduced. The question was whether these transients would succeed in capturing attention. The signature of capture success was longer RTs for the form change and onset, versus the baseline, trials.

\section{Method}

Participants. There were 20 observers recruited from the psychology undergraduate pool, all of whom had normal or correctedto-normal vision. They participated in partial fulfillment of course requirements.

Procedure. The observers viewed the displays freely from a distance of $50 \mathrm{~cm}$. The presentation frames were synchronized with the $100-\mathrm{Hz}$ vertical refresh of the monitor. The four objects were placed around the circumference of an imaginary circle, the diameter of which subtended a visual angle of approximately $8^{\circ}$; this was comparable with the Theeuwes (1991) display, which had a diameter of $8.4^{\circ}$. The height and width of an object subtended visual angles of approximately $1.2^{\circ}$ and $1^{\circ}$, respectively. The fixation symbol, arrow cue, placeholders, onset spots, and letters all had the same luminance $\left(30 \mathrm{~cd} / \mathrm{m}^{2}\right)$. The background luminance was $60 \mathrm{~cd} / \mathrm{m}^{2}$. The placeholders' locations on the imaginary circle varied from trial to trial, but the adjacent placeholders were always equidistant from each other. The intertrial interval was $750 \mathrm{msec}$.

Each block included 40 trials, of which half had an $E$ and the other half an $H$ as the target. The 20 trials were divided among the various conditions as follows: The long and short stimulus onset asynchrony (SOA) conditions had 8 trials apiece (6 onset, 1 form change, and 1 baseline), and the simultaneous condition had 4 trials ( 3 onset and 1 no-onset). ${ }^{3}$ Thus, onset trials constituted $75 \%$ of all trials $(15 / 20)$. Only 3 out of 20 trials (15\%) had no onset visual transient. Each observer went through 11 blocks, and the data from the first (practice) block were not analyzed.

\section{Results and Discussion}

To determine whether there was a speed-accuracy trade-off in the data, the accuracy rates of the three onsetabsent conditions were compared in a one-way ANOVA. The effect was marginally significant $[F(2,38)=2.875$, $\left.p<.07, \eta_{\mathrm{p}}^{2}=.13\right]$. For the simultaneous condition, accuracy $(M=.96)$ was lower than in the long- and short-SOA conditions (both $M \mathrm{~s}=.99),{ }^{4}$ and the mean RT for the si- 


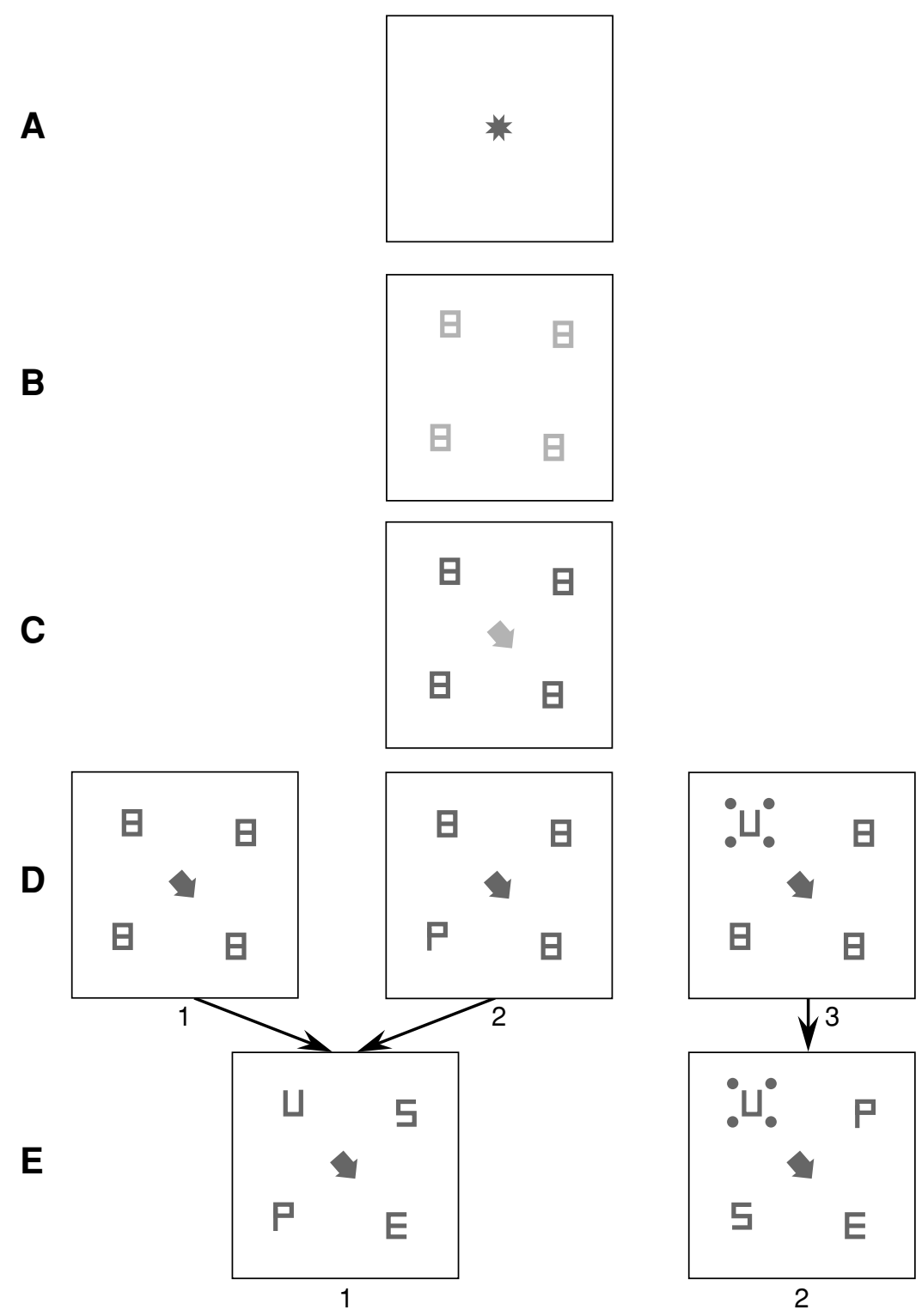

Figure 1. Schematic representation of a single trial. After the fixation symbol (A) appeared, the placeholders $(B)$ were ramped on. When they achieved their final luminance, the central arrow cue (C) was ramped on. On some trials, a placeholder turned into a distractor letter (D2) or four spots appeared around a distractor letter (D3) either $60 \mathrm{msec}$ or $200 \mathrm{msec}$ before the target appeared (E1 and E2). For the simultaneous condition (onset-target SOA $=0 \mathrm{msec}$ ), the central arrow cue was invisible until frame E. In the experiments, there was no outline framing the stimuli.

multaneous condition was also longer $(M=628 \mathrm{msec}$, vs. $M=467$ and $479 \mathrm{msec}$ for the long- and short-SOA conditions, respectively). This pattern of results is inconsistent with a speed-accuracy trade-off. The mean RTs as a function of SOA and trial type are depicted in Figure 2.

Next, we show that when the target location was not precued, the onset spots captured attention, replicating a robust finding in the literature (Jonides, 1981; Remington, Johnston, \& Yantis, 1992; Yantis, 1998, 2000). The RTs of the onset trials $(M=651 \mathrm{msec}, S D=94)$ were significantly longer than those of the onset-absent trials $(M=628 \mathrm{msec}$,
$S D=77)\left[F(1,19)=13.712, p<.005, \eta_{\mathrm{p}}^{2}=.42\right]$. The accuracy rates for these two conditions, however, were comparable $(M=.96$ and .95 for the baseline and onset conditions, respectively), indicating, once again, that no speed-accuracy trade-off took place. When attention was in a diffuse state, the onset spots succeeded in capturing attention.

When attention was precued, however, the same onset spots failed to capture attention. A 2 (SOA: long vs. short) $\times 3$ (trial type: baseline vs. form change vs. onset) ANOVA revealed that the RTs for the three types of trials were comparable $\left[F(2,38)=1.927, p>.1, \eta_{\mathrm{p}}^{2}=\right.$ 


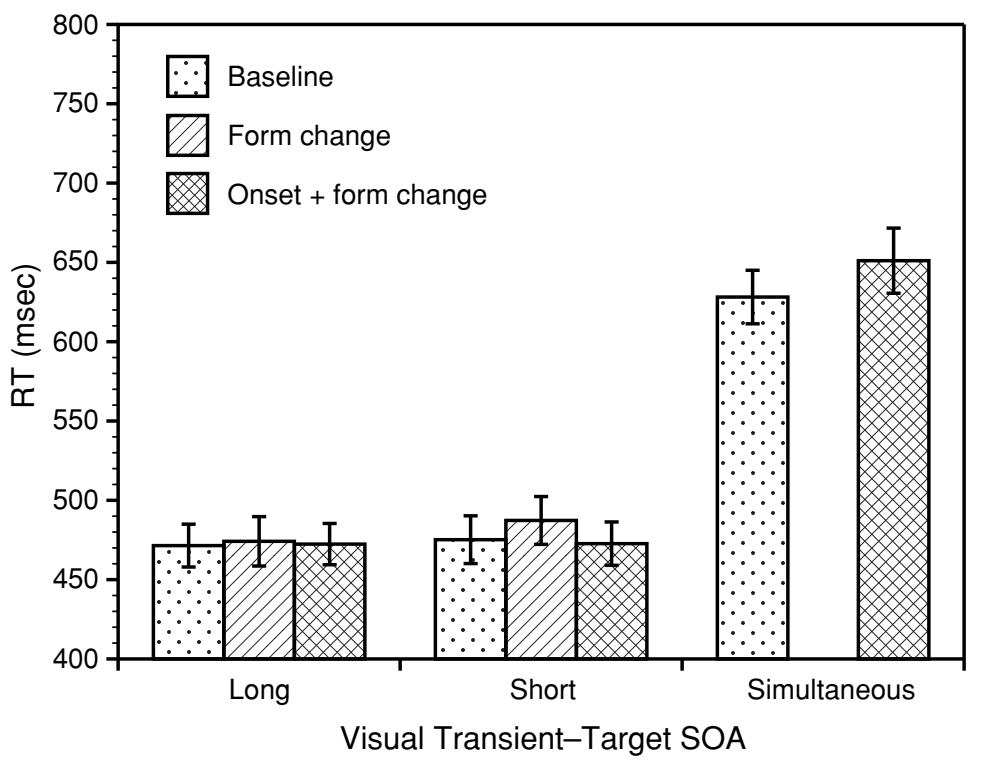

Figure 2. Experiment 1: Mean reaction times (RTs) as a function of type of visual transient and visual transient-target SOA. Error bars $=1 S E$.

.09]. There was also no significant difference between the long- and short-SOA conditions $[F(1,19)=1.700, p>$ $\left..2, \eta_{\mathrm{p}}^{2}=.08\right]$, and the interaction effect was not reliable $\left[F(2,38)=1.085, p>.3, \eta_{\mathrm{p}}^{2}=.05\right]$. These findings replicate Theeuwes's (1991) results. Furthermore, in the form change condition (created by offsetting distractor line segments), the visual transient did not capture attention, even though transients of the same type accompanied target revelation in all conditions. To anticipate the results of the other experiments, the form change condition was generally not effective in capturing attention.

On the face of it, these results support the interpretation that when the target location has been prioritized, top-down control prohibits attentional capture. It would appear that onsets fail the intentionality criterion, and thus cannot be said to capture attention automatically. In the next experiment, we reduced onset frequency to less than $20 \%$, in order to find out whether the same results would be obtained when we restricted the frequency of onset appearance, and thereby made them relatively novel.

\section{EXPERIMENT 2}

In Experiment 1, the onset appeared on $75 \%$ of the trials. When the spots appear again and again, over time the observer would come to expect their appearance at some point during the trial. Thus, when the spots appeared they were unlikely to draw the observer's attention to their location, even though they appeared as abrupt onsets. Experiment 2 was identical to Experiment 1 in all respects, except that the onset spots appeared on $18.75 \%$ of the trials, making their appearance relatively rare. This should have, presumably, preserved the novelty of the abrupt onset. The question was whether preserving this novelty would enhance its effectiveness in capturing attention.

\section{Method}

The procedure was identical to that in Experiment 1, except that each block contained 32 trials, with the letter $E$ or $H$ appearing as target on 16 of the trials. Of these 16 trials, 6 apiece ( 4 baseline, 1 form change, and 1 onset) were in the long- and short-SOA conditions, and 4 ( 3 no-onset and 1 onset) were in the simultaneous condition. Thus, the onset appeared on $6(18.75 \%)$ of the 32 trials.

Fifteen new participants were recruited from the same pool as in Experiment 1. Each went through 13 blocks of trials, and data from the first (practice) block were not analyzed.

\section{Results}

To ascertain that there was no speed-accuracy tradeoff, a one-way ANOVA was conducted for the accuracy data of the three onset-absent conditions. There was an overall difference in accuracy $[F(2,28)=8.663, p<.001$, $\left.\eta_{\mathrm{p}}^{2}=.40\right]$, with poorer performance in the simultaneous $(M=.97)$ than in the precue $(M \approx .99)$ conditions, where performance was close to ceiling. But the less-accurate simultaneous condition also produced RTs that were $100 \mathrm{msec}$ longer, implying that speed-accuracy trade-off was not an issue here. The mean RTs as a function of SOA and trial type are depicted in Figure 3 (left panel).

When there was no precue (simultaneous condition), the appearance of the spots led to reliably longer RTs than when the spots were absent $[F(1,14)=9.363, p<.01$, $\left.\eta_{\mathrm{p}}^{2}=.40\right]$, replicating Experiment 1. The critical question was whether the form change/onset conditions would also produce longer RTs when the target location was precued.

The latency data for the precue conditions were subjected to a 2 (SOA: long vs. short) $\times 3$ (trial type: baseline vs. form change vs. onset) ANOVA. RTs differed across the trial type variable $\left[F(2,28)=5.342, p<.01, \eta_{\mathrm{p}}^{2}=\right.$ .28]. Overall, the long-SOA condition yielded significantly longer RTs $\left[F(1,14)=5.428, p<.05, \eta_{\mathrm{p}}^{2}=.28\right]$. 


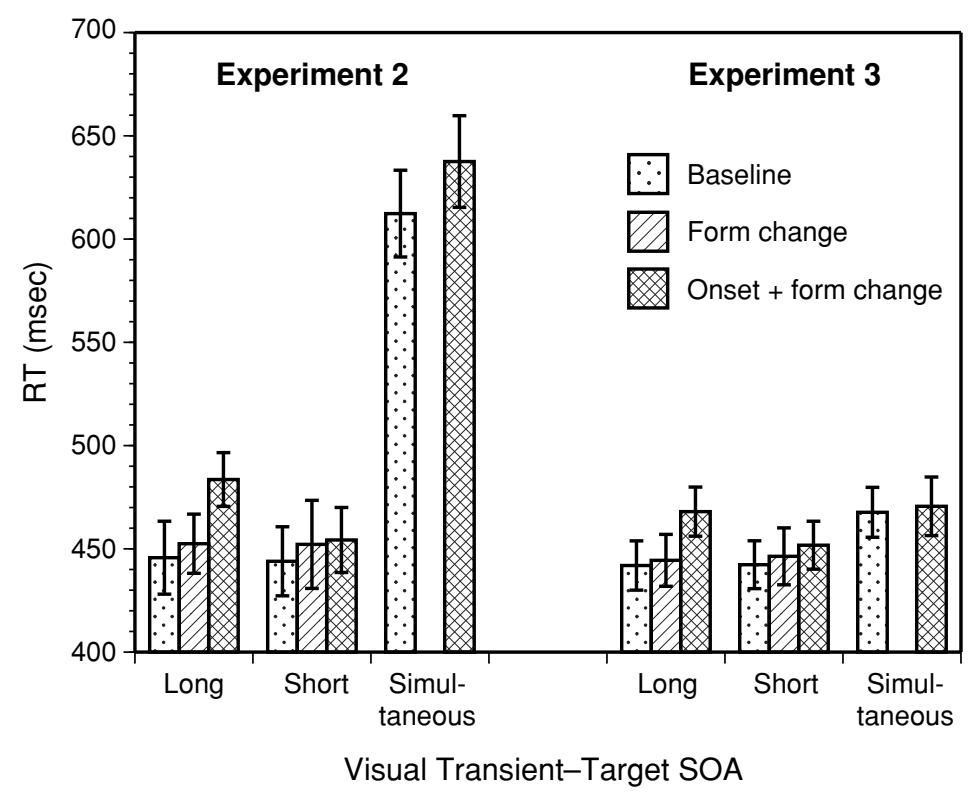

Figure 3. Experiments 2 (left) and 3 (right): Mean reaction times (RTs) as a function of type of visual transient and visual transient-target SOA. Error bars $=1 S E$.

There was also a marginally significant SOA $\times$ trial type interaction $\left[F(2,28)=3.233, p<.06, \eta_{\mathrm{p}}^{2}=.19\right]$, which prompted us to examine separately the effects at the long and short lags. For the long-SOA condition, only the onset trials led to RTs significantly longer than baseline $\left[F(1,14)=15.421, p<.005, \eta_{\mathrm{p}}^{2}=.52\right]$. The 7-msec difference between the form change and baseline trials was not reliable $\left[F(1,14)=2.449, p>.1, \eta_{\mathrm{p}}^{2}=.15\right]$. For the short-SOA condition, the three trial type conditions did not differ significantly from each other $(F<1)$.

These results were quite clear: When the frequency of onsets was reduced to less than $20 \%$, RTs were significantly longer when the four spots appeared $200 \mathrm{msec}$ before the target. To test the generality of this result, we ran another experiment with small variations in the experimental parameters. The onset frequency was increased to $25 \%$, and the critical variation was the luminance of the onset spots, which were "white" $\left(120 \mathrm{~cd} / \mathrm{m}^{2}\right)$, whereas all the other objects on screen (including the target) were "dark gray" $\left(30 \mathrm{~cd} / \mathrm{m}^{2}\right)$. By making the contrast (and polarity) of the onset spots quite different from those of the target, the aim was to allow the spots to be filtered out more efficiently. Thus, there ought to have at least been weakening of the capture effects, if not their complete eradication. Another group of 26 students participated under the same motivational conditions.

Unsurprisingly, when attention was diffuse (the simultaneous condition), the four white spots captured attention $\left[F(1,25)=24.084, p<.001, \eta_{\mathrm{p}}^{2}=.48\right]$. But, crucially, when the target location was cued and the onset spots appeared before the target was revealed, capture was also observed. For the long-SOA condition, both the onset and form change conditions produced reliably longer RTs $\left[F(1,25)=15.116, p<.001, \eta_{\mathrm{p}}^{2}=.38\right.$, and $F(1,25)=$
$5.727, p<.05, \eta_{\mathrm{p}}^{2}=.19$, respectively]. For the short-SOA condition, RTs were significantly longer in the onset trials (in comparison with the baseline) $[F(1,25)=9.098, p<$ $\left..01, \eta_{\mathrm{p}}^{2}=.27\right]$ but not in the form change trials $(F<1)$. The important point here is that the onset spots had a luminance very different from the target, which presumably should have facilitated filtering them out. But RTs were still reliably longer when the white spots appeared abruptly.

\section{Discussion}

The similarities and differences in the results of Experiments 1 and 2 were quite evident. For the diffuseattention conditions, the results of the experiments were by and large comparable: ${ }^{5}$ RTs were reliably longer for the onset condition, suggesting that the spots captured attention. When the target was precued, though, the results were different: RTs were comparable for the baseline, form change, and onset trials when onset frequency was high (Experiment 1,75\%), but not when onset frequency was low (Experiment 2, <20\%). ${ }^{6}$

Since the central arrow cue preceded the visual transients by at least $400 \mathrm{msec}$, there should have been sufficient time for attention to be deployed at the target location by the time the form change or onset appeared. The longer RTs for the onset condition therefore imply that attention was captured by the abrupt appearance of the spots. Capture was clearly observed when the onsets preceded target revelation by $200 \mathrm{msec}$, but when the SOA was short $(60 \mathrm{msec})$ capture was not always reliably found. This result contrasted with a finding of Theeuwes et al. (2000), who reported reliable (singleton) capture effects only when the singleton appeared shortly before the target (100 msec or less). We discuss this seeming discrepancy 
more fully in the General Discussion. At this juncture, it is perhaps helpful to be reminded that the observers in Theeuwes et al.'s experiments were in a diffuse attentional state before the singleton appeared. One interpretation of our results is that attention does not disengage immediately from the prioritized (target) location when the onset appears, but that there is some initial inertia before attention shifts to the capture site. If the target appears during this window, then the shift will not materialize, and no capture will be evident. This initial inertia appears to be modulated by the salience of the onset stimulus; when the onset spots were white, we obtained evidence of capture even in the short-SOA condition.

Offset transients (which obtained in the form change condition) were much less effective than the onset transients in capturing attention, which is consistent with the findings of Theeuwes (1991, Experiment 2). Recall that in our experiment, the target display was revealed when all the placeholders shedded line segments. Yet in the form change condition, which also consisted of one (distractor) placeholder shedding line segments in a fashion identical to the target, the distractor failed to capture attention. This is somewhat surprising in light of Gibson and Kelsey's (1998) results, which implied that the success of a particular visual feature in capturing attention depends on its match with the features present when the target display appears. In their experiments, however, the target location was not precued (i.e., attention was diffuse). This difference suggests that the nature of top-down modulation could well depend on whether attention has been prioritized.

For the onset stimulus, the critical factor modulating its potency was the frequency with which it appeared. The contrast between Experiments 1 and 2 shows that when onset transients are repeatedly introduced, they lose their attention-attracting capacity. According to Sokolov (1975), when a stimulus is repeatedly presented, its stimulation profile over time is incorporated into the observer's neuronal model, and once this occurs, the stimulus no longer triggers an OR. Exogenous control may be seen as part of the OR to peripheral stimulation. When the OR is suppressed, attention is not captured.

The results of Experiment 2 show that onsets pass the intentionality criterion. Even when attentional control has been prioritized elsewhere, visual transients created by onsets can capture attention, but for this to happen, it is crucial that the novelty of the capture stimulus be preserved.

\section{EXPERIMENT 3}

The main aim of Experiment 3 was to allow an even more stringent test of the prioritization hypothesis. Here, attentional prioritization of a single location was achieved by constraining the target to be in the same place throughout the experiment. When target location changes from trial to trial, focusing may not be optimized (Miller, 1991). For example, a distractor from the previous trial could well have occupied the current target position. If the distractor locations had been inhibited to improve target processing, and this inhibition persisted across trials, attentional deployment at the target location could be less than optimal. Fixing the target to a single location throughout allows attention to be focused more narrowly at only that location (Bravo \& Nakayama, 1992). This manipulation will also address the issue of more precise tuning of top-down control of attention with practice (see, e.g., Kim \& Cave, 1999; Warner et al., 1990). With the target at the same location throughout, one might expect that after the practice block, precise attentional guidance to that one location should probably be the norm. The question is whether in this context attentional capture by an infrequently occurring stimulus could, at last, be evaded.

\section{Method}

The design and procedure were identical to those in Experiment 2, with the critical difference that the location of the target remained fixed throughout the experiment. The observers were explicitly told about this feature. Although the arrow cue was entirely superfluous after Trial 1, it nevertheless appeared on every trial. The observers were briefed to fixate on the arrow.

The participants were 16 students drawn from the same pool used in the previous experiments. Each was presented with 13 blocks, and the data from the first (practice) block were not analyzed.

\section{Results and Discussion}

In Experiments 1 and 2, observers were less accurate in the simultaneous than in the precued conditions. In Experiment 3, a one-way ANOVA of accuracy scores for the three onset-absent conditions showed no reliable difference $(F<1)$. This result contrasted with those found in Experiments 1 and 2, where accuracy in the simultaneous condition was significantly lower. Although the simultaneous condition was truly a diffuse-attention condition in Experiments 1 and 2, the fact that the target location did not change throughout Experiment 3 made the simultaneous condition, in effect, a focused attention condition. ${ }^{7}$ The mean RTs as a function of SOA and trial type are depicted in Figure 3 (right panel).

Since observers knew in advance where the target would appear in Experiment 3, latencies in the simultaneous (no arrow cue) condition were, unsurprisingly, shorter than in Experiments 1 and 2. This advance knowledge of target location also effectively protected the observers from attention capture when the onset spots appeared as the target was being revealed. The 2-msec difference between the mean RTs in the onset condition $(M=470 \mathrm{msec}$, $S D=58)$ and the onset-absent condition $(M=468 \mathrm{msec}$, $S D=50)$ was not reliable $(F<1)$. This result may be considered a conceptual replication of Yantis and Jonides (1990): When the onset appeared simultaneously with a target whose location was known in advance, capture did not happen.

The critical question was whether the observers would be similarly protected when the onset appeared before the target. The results of a 2 (SOA: long vs. short) $\times 3$ (trial type: baseline vs. form change vs. onset) ANOVA of the relevant precue conditions were, in essence, similar to those in Experiment 2. There was no SOA effect $\left[F(1,15)=1.117, p>.05, \eta_{\mathrm{p}}^{2}=.07\right]$, but there was an 
overall trial type effect $\left[F(2,30)=4.169, p<.05, \eta_{\mathrm{p}}^{2}=\right.$ $.22]$. Crucially, there was also an SOA $\times$ trial type interaction effect $\left[F(2,30)=5.454, p<.01, \eta_{\mathrm{p}}^{2}=.27\right]$.

For the short-SOA condition, RTs were essentially comparable for all three types of trials $\left(F_{\mathrm{S}}<1\right)$, but for the long-SOA condition, the RTs were significantly different $\left[F(2,30)=7.612, p<.005, \eta_{\mathrm{p}}^{2}=.28\right]$. RTs for the form change condition and the baseline were not different with a long SOA $(F<1)$. The onset condition, however, had significantly longer RTs than did the baseline condition $\left[F(1,15)=13.303, p<.005, \eta_{\mathrm{p}}^{2}=.47\right]$.

There were two main findings. First, even when the target position remained fixed throughout the experiment, attentional capture could not be evaded if the spots abruptly onset $200 \mathrm{msec}$ before the target appeared. Second, when the onset appeared simultaneously with the target or preceded it by only a short lag, capture effects were not evident.

\section{GENERAL DISCUSSION}

In a diffuse attentional state, a stimulus that onsets abruptly almost invariably captures attention, showing that attention can be controlled in a bottom-up fashion. Yantis and Jonides (1990) examined whether the same onset is equally effective when attention has been precued to a location in which the target is guaranteed to appear. They argued that if an onset still succeeded in this scenario, the intentionality criterion of automaticity could be considered fulfilled. Their results showed that onsets failed this criterion. Using a slightly different procedure, Theeuwes (1991) reported results consistent with their conclusion.

We examined the same question using a variation of Theeuwes's (1991) paradigm. We ensured, first, that the central cue was $100 \%$ valid, and second, that visual transients never appeared at or near the target location (i.e., that the onset transients were $100 \%$ invalid). The target was always a no-onset object. With these constraints in place, observers should have had no incentive to allocate attentional resources to the location of the onset transients.

\section{Main Findings}

There were two main variables in this set of experiments: form change/onset frequency and form change/ onset-target SOA. The results may be summarized as follows.

1. The onset stimulus captured attention when it appeared less frequently and at least $200 \mathrm{msec}$ before the target (Experiment 2). Even when the target location was fixed throughout the experiment, which presumably would have facilitated attentional focusing (Experiment 3), attentional capture could not be evaded. When the onset appeared frequently (Experiment 1), though, it failed altogether to capture attention.

2. When the onset appeared $60 \mathrm{msec}$ before the target, evidence of capture was elusive (Experiments 2 and 3 ). In line with this finding, when onset spots appeared simultaneously with the target ( 0 -msec condition, Experiment 3$)$, they also failed to capture attention. There is some evi- dence that the salience of the onset object modulated the SOA effect. When the spots had a luminance $\left(120 \mathrm{~cd} / \mathrm{m}^{2}\right)$ that differed markedly from the luminance of the other stimuli $\left(30 \mathrm{~cd} / \mathrm{m}^{2}\right)$, onsets that appeared $60 \mathrm{msec}$ before the target did succeed in capturing attention.

3. Visual transients created by offsetting line segments of a placeholder to form a distractor letter (the form change condition) almost invariably failed in capturing attention.

We discuss these results below.

\section{Onset Frequency}

The contrast between the results for Experiments 1 and 2 shows that capture cannot be adequately explained by a theory that assumes that onset transients, in themselves, automatically attract attention. Rather, the frequency with which the onset appears modulates its effectiveness. A frequently appearing stimulus would lose its novelty, over time, and consequently its effectiveness in capturing attention. At the same time, it is important to note that rarity does not, in itself, guarantee capture success (see, e.g., Gibson \& Jiang, 1998; Yantis \& Egeth, 1999, Experiment 9). Successful capture appears to be achieved only if a stimulus onsets abruptly and infrequently.

When the onset's appearance was frequent (Experiment 1), attentional capture was only observed when the target location was not precued (i.e., when attention was diffuse). The question is, why should the onset stimulus's frequent appearance rob it of its capacity to attract attention exogenously? Yantis and his colleagues (e.g., Yantis, 1998; Yantis \& Hillstrom, 1994) made the important observation that although an onset is accompanied by local luminance changes, it is not the luminance change per se that is critical. Rather, attentional capture results because an onset signifies the advent of a new object.

The notion of a "new" object may be considered from two different perspectives. Consider, first, the single trial. In these experiments, the baseline condition was one in which the display remained unchanged until all four placeholders shed line segments to reveal the camouflaged letters. For the form change and onset trials, visual transients were introduced at a distractor location before the target was revealed. When such visual transients appear, they produce stimulation different from the old (unchanging) stimulation prior to their appearance. From the perspective of a single trial, then, the appearance of the onset and form change transients would always be new, but from the wider perspective of what had transpired in the previous trials (e.g., the observer's episodic memory), the onset spots could be considered "new" only on their first occurrence. If the spots are presented infrequently, on the other hand, their appearance, though not entirely new, would still be unexpected, and thus might have novelty value. Increasing the frequency of the onset's appearance would not affect its status as a new object in the narrow context of a single trial, but the change would surely undermine its novelty. If the potency of the onset in capturing attention rests on its status as a novel object, the implication is that the frequency with which the onset appears should have a bearing on its power to attract attention exogenously. 
The position advanced by Yantis and colleagues, that the onset captures attention by virtue of its status as a new object, in a broad sense is prefigured in Sokolov's (1975) notion of the orienting response. To recapitulate, as the observer (implicitly) learns about the sequence of events that make up each trial, an internal representation-the neuronal model - is soon established. It contains information such as the sequence of events in the trial, changes in stimulation over time, and so forth. In other words, the neuronal model represents the expectations of how a typical trial should unfold over time. As the trial progresses, afferent stimulation is continuously matched to the neuronal model, and when there is a match, the OR is inhibited. When a mismatch is detected, however, an OR is triggered.

If visual transients appear rarely (Experiments 2 and 3 ), they are not likely to be incorporated into the neuronal model. Thus, when transients do appear, the afferent stimulation from the display fails to match the neuronal model, thereby triggering exogenous orienting. If the transients are salient, the mismatch would be larger, thereby producing a larger OR. On the other hand, onsets that appear frequently (e.g., in $75 \%$ of the trials in Experiment 1) will soon have their stimulation profile incorporated into the neuronal model. When this happens, the visual input following the spots' appearance matches the neuronal model, inhibiting the OR and thus preventing capture. Our results are broadly consistent with this account.

In Experiment 1, the baseline trials were rare in comparison with the onset trials. If observers expected visual transients to appear before the target and these transients failed to materialize (i.e., a baseline trial), there should similarly have been a mismatch between the afferent stimulation and the neuronal model, which would have led to the triggering of an OR. There was no evidence of attentional capture for two reasons. First, when attention is captured by a stimulus (say, an onset), attention shifts to its location and engages there. When the onset unexpectedly fails to materialize, though, there is no single location to which attention is inexorably drawn. Observers may have expected the four spots to appear in the display, but since the onset could appear in any of the three distractor locations, they could not predict for any single trial which of the three locations would contain the spots. Second, the central cue-onset SOA varied from 400 to $540 \mathrm{msec}$, which may have made it difficult to predict the exact moment of the spots' appearance. As a result, attention probably stayed rooted where it had already been deployed. The RTs for the (rare) baseline trials were therefore no longer than those for the (predominant) onset trials.

\section{Onset-Target SOA}

Research examining attentional cuing has shown that attentional control via peripheral and central cues follows different time courses (Cheal \& Lyon, 1991; Jonides, 1981; Müller \& Rabbitt, 1989). Attentional deployment at the location of the peripheral cue is rapid ( $<100 \mathrm{msec})$, but it takes $300 \mathrm{msec}$ or more for attention to be focused at the centrally cued location. In addition, when attention is captured by a peripheral cue, this attention is capable of swiftly disengaging from the capture site (Kim \& Cave, 1999; Theeuwes et al., 2000). Thus, if the target only appears after a long SOA, attention would long since have disengaged from the onset location, ensuring no delay in engaging it at the target site. In this case, the signature of capture might not be apparent.

The observations of Kim and Cave (1999) and Theeuwes et al. (2000) pertained to the time course of disengagement from a peripherally cued location when the attentional state was initially diffuse. We studied the case in which attention had already been deployed and examined the time course of attentional disengagement from the centrally cued location. Our results were quite the opposite of the previous findings, in that reliable effects were only observed for the long onset-target SOA, suggesting that attentional disengagement from a centrally cued location was sluggish. Thus, just as attentional engagement via a central, symbolic cue was slow, attentional disengagement from an endogenously cued location also appeared to take a long time.

Theeuwes et al. (2000) argued that a particular range of SOAs is optimal for gauging whether capture does, indeed, occur. Our results suggest that similar constraints pertain to the case in which attention has been initially focused: There appears to be some minimum SOA below which attentional capture is not apparent. Indeed, we found that when the onset preceded the target by $60 \mathrm{msec}$, evidence of capture could not be reliably found. Capture was consistently observed only when the onset-target SOA was much longer, $200 \mathrm{msec}$.

Why would disengagement from a centrally cued location be so sluggish? Our observations of capture at $200 \mathrm{msec}$, but not at 60 or $0 \mathrm{msec}$, suggest that there could have been an initial suppression of attention disengaging from the target location, where the target was guaranteed to appear. Such a suppression of disengagement would probably be more effective when attention has just been engaged. At the same time, there probably would be some kind of time-out procedure allowing disengagement to occur later. Over time, the suppression would relax gradually, and if the target was still not revealed, there would be an increasing chance that attention would shift from the cued location to engage with the next object in the attentional priority queue. Thus, it would be harder to wrest attention away if the onset appeared a short time before the target appeared. Helmholtz (1925) proposed a somewhat similar idea: "As soon as interest in one object has been exhausted, and there is no longer anything new in it to be perceived, it is transferred to something else, even against our will" (p. 498).

\section{Offset Transients}

Whether offset transients are capable of capturing attention is a vexed issue. Some researchers (e.g., Yantis \& Jonides, 1984) have reported that offsets are not effective, but others (e.g., Miller, 1989; Theeuwes, 1991) reported that offsets could succeed under some circumstances. In our experiments, the target was revealed when line seg- 
ments disappeared from a placeholder. That is, offset transients accompanied target appearance. Thus, it might be expected that the visual system should therefore have been primed to respond to the offset transients. Recently, Gibson and Kelsey (1998) and Atchley, Kramer, and Hillstrom (2000) showed that offsets could capture attention, provided that offset transients also signaled the target's appearance. The results of our experiments appear to contradict their findings. A critical difference between the two paradigms probably explains these seemingly contradictory results. Whereas the previous researchers looked at the case in which attention had yet to be prioritized (i.e., diffuse attention), we examined a situation in which attention was precued to the target location. It appears that offsets do not have the same potency as onsets in capturing attention that has already been prioritized, even when monitoring offset transients would have been part of the attentional set.

\section{Conclusion}

We asked whether onsets capture attention automatically, even when attention has already been cued to a location in which a target was guaranteed to appear. The results strongly suggest that, so long as the onset event is novel, capture results even when attention has been prioritized elsewhere. But because disengagement from a cued location is sluggish, the signature of capture may not be apparent if the target appeared very shortly after the onset. With a long enough SOA between the onset and the target appearance, the signs of attentional capture can be quite clearly observed.

\section{REFERENCES}

Atchley, P., Kramer, A. F., \& Hillstrom, A. P. (2000). Contingen capture for onsets and offsets: Attentional set for perceptual transients. Journal of Experimental Psychology: Human Perception \& Performance, 26, 594-606.

Bravo, M. J., \& NAKAYAMA, K. (1992). The role of attention in different visual-search tasks. Perception \& Psychophysics, 51, 465-472.

CheAL, M., \& LYON, D. R. (1991). Central and peripheral precuing of forced-choice discrimination. Quarterly Journal of Experimental Psychology, 43A, 859-880.

Folk, C. L., \& Remington, R. [W.] (1998). Selectivity in distraction by irrelevant featural singletons: Evidence for two forms of attentional capture. Journal of Experimental Psychology: Human Perception \& Performance, 24, 847-858.

Folk, C. L., \& Remington, R. [W.] (1999). Can new objects override attentional control settings? Perception \& Psychophysics, 61, 727739.

Folk, C. L., Remington, R. W., \& Johnston, J. C. (1992). Involuntary covert orienting is contingent on attentional control settings. Journal of Experimental Psychology: Human Perception \& Performance, 18, 1030-1044.

Gibson, B. S., \& Jiang, Y. (1998). Surprise! An unexpected color singleton does not capture attention in visual search. Psychological Science, 9, 176-182.

Gibson, B. S., \& Kelsey, E. M. (1998). Stimulus-driven attentional capture is contingent on attentional set for displaywide visual features. Journal of Experimental Psychology: Human Perception \& Performance, 24, 699-706.

Helmholtz, H. von (1925). Helmholtz's treatise on physiological optics (Vol. 3). Rochester, NY: Optical Society of America.

JAMES, W. (1890). The principles of psychology. New York: Holt.

JONIDES, J. (1981). Voluntary versus automatic control over the mind's eye's movement. In J. Long \& A. Baddeley (Eds.), Attention and performance $I X$ (pp. 187-203). Hillsdale, NJ: Erlbaum.

KIM, M.-S., \& CAVE, K. R. (1999). Top-down and bottom-up attentional control: On the nature of interference from a salient distractor. Perception \& Psychophysics, 61, 1009-1023.

Klein, R. M., \& Shore, D. I. (2000). Relations among modes of visual orienting. In S. Monsell \& J. Driver (Eds.), Control of cognitive processes: Attention and performance XVIII (pp. 195-208). Cambridge, MA: MIT Press.

LABERGE, D. (1981). Automatic information processing. In J. Long \& A. Baddeley (Eds.), Attention and performance IX (pp. 173-186). Hillsdale, NJ: Erlbaum.

LogAn, G. D. (1981). Attention, automaticity, and the ability to stop a speeded choice response. In J. Long \& A. Baddeley (Eds.), Attention and performance $I X$ (pp. 205-222). Hillsdale, NJ: Erlbaum.

Miller, J. (1989). The control of attention by abrupt visual onsets and offsets. Perception \& Psychophysics, 45, 567-571.

Miller, J. (1991). The flanker compatibility effect as a function of visual angle, attentional focus, visual transients, and perceptual load: A search for boundary conditions. Perception \& Psychophysics, 49, 270-288.

Müller, H. J., \& Rabbitt, P. M. A. (1989). Reflexive and voluntary orienting of visual attention: Time course of activation and resistance to interruption. Journal of Experimental Psychology: Human Perception \& Performance, 15, 315-330.

Neumann, O. (1984). Automatic processing: A review of recent findings and a plea for an old theory. In W. Prinz \& A. F. Sanders (Eds.), Cognition and motor processes (pp. 257-291). Berlin: Springer.

Pashler, H., Johnston, J. C., \& Ruthruff, E. (2001). Attention and performance. Annual Review of Psychology, 52, 629-651.

Posner, M. I. (1978). Chronometric explorations of mind: The third Paul M. Fitts lectures delivered at the University of Michigan, September, 1976. Hillsdale, NJ: Erlbaum.

Remington, R. W., Johnston, J. C., \& Yantis, S. (1992). Involuntary attentional capture by abrupt onsets. Perception \& Psychophysics, 51, 279-290.

Sokolov, E. N. (1975). The neuronal mechanisms of the orienting reflex. In E. N. Sokolov \& O. S. Vinogradova (Eds.), Neuronal mechanisms of the orienting reflex (pp. 217-235). Hillsdale, NJ: Erlbaum.

Theeuwes, J. (1991). Exogenous and endogenous control of attention: The effect of visual onsets and offsets. Perception \& Psychophysics, 49, 83-90.

Theeuwes, J. (1992). Perceptual selectivity for color and form. Perception \& Psychophysics, 51, 599-606.

Theeuwes, J. (1995). Temporal and spatial characteristics of pre-attentive and attentive processing. Visual Cognition, 2, 221-233.

Theeuwes, J., Atchley, P., \& Kramer, A. F. (2000). On the time course of top-down and bottom-up control of visual attention. In S. Monsell \& J. Driver (Eds.), Control of cognitive processes: Attention and performance XVIII (pp. 105-124). Cambridge, MA: MIT Press.

TODD, J. T., \& VAN GELDER, P. (1979). Implications of a transient-sustained dichotomy for the measurement of human performance. Journal of Experimental Psychology: Human Perception \& Performance, 5, 625638

Warner, C. B., Juola, J. F., \& Koshino, H. (1990). Voluntary allocation versus automatic capture of visual attention. Perception \& Psychophysics, 48, 243-251.

Yantis, S. (1998). Control of visual attention. In H. Pashler (Ed.), Attention (pp. 223-256). Hove, U.K.: Psychology Press.

YANTIS, S. (2000). Goal-directed and stimulus-driven determinants of attentional control. In S. Monsell \& J. Driver (Eds.), Control of cognitive processes: Attention and performance XVIII (pp. 73-103). Cambridge, MA: MIT Press.

YANTIS, S., \& EGETH, H. E. (1999). On the distinction between visual salience and stimulus-driven attentional capture. Journal of Experimental Psychology: Human Perception \& Performance, 25, 661-676.

Yantis, S., \& Hillstrom, A. P. (1994). Stimulus driven attentional capture: Evidence from equiluminant visual objects. Journal of Experimental Psychology: Human Perception \& Performance, 20, 95-107.

Yantis, S., \& Johnson, D. N. (1990). Mechanisms of attentional priority. Journal of Experimental Psychology: Human Perception \& Performance, 16, 812-825. 
YANTIS, S., \& Jonides, J. (1984). Abrupt visual onsets and selective attention: Evidence from visual search. Journal of Experimental Psychology: Human Perception \& Performance, 10, 601-621.

YANTIS, S., \& Jonides, J. (1990). Abrupt visual onsets and selective attention: Voluntary versus automatic allocation. Journal of Experimental Psychology: Human Perception \& Performance, 16, 121-134.

\section{NOTES}

1. A no-onset object is revealed when several line segments that camouflage it are removed.

2. Because the central arrow cue was ramped on (see below), the SOA between the initial appearance of the arrow and the onset/form change was longer than the nominal $400 \mathrm{msec}$ (measured from the moment at which the arrow achieved its maximum luminance of $30 \mathrm{~cd} / \mathrm{m}^{2}$ ).

3. The baseline conditions for the long- and short-SOA conditions were identical. The distinction is merely notional.

4. The accuracy rates for the precue conditions were comparable. A 2 $(\mathrm{SOA}) \times 3$ (baseline vs. form change vs. onset) ANOVA revealed no main effects $(F \mathrm{~s}<1)$ nor any interaction effect $[F(2,38)=1.066, p>.3]$.

5. Formally, a 2 (experiment) $\times 2$ (onset: absent vs. present) mixed ANOVA showed only an onset effect $[F(1,33)=22.741, p<.001$, $\left.\eta_{\mathrm{p}}^{2}=.41\right]$. All other effects were not reliable $(F<1)$.

6. Again formally, a 2 (experiment) $\times 2$ (long vs. short SOA) $\times 3$ (trial type: baseline vs. form change vs. onset) mixed ANOVA showed no overall effect of experiment $(F<1)$, but there was a reliable experiment $\times \mathrm{SOA}$ interaction effect $\left[F(1,33)=10.307, p<.005, \eta_{\mathrm{p}}^{2}=.23\right]$ and, crucially, an experiment $\times$ trial type effect $[F(2,66)=5.810, p<$ $\left..005, \eta_{\mathrm{p}}^{2}=.15\right]$. The three-factor interaction effect was not reliable.

7. This, however, raises the possibility that the observers may not have fixated on the (essentially redundant) central arrow cue, but rather on the placeholder that masked the target. (Eye movements were not monitored.) There are two lines of evidence that do not support this view. First, if observers had fixated the placeholder masking the target, there should have been no difference in the RTs between the arrow-present (precue) and no-arrow (simultaneous) conditions. A one-way ANOVA comparing the three different onset-absent conditions showed that, despite the arrow cue being redundant, the mean RT for the precue conditions was still $25 \mathrm{msec}$ shorter than the no-arrow-cue condition $[F(1,15)=37.729$, $\left.p<.001, \eta_{\mathrm{p}}^{2}=.71\right]$. Second, a comparison of the baseline conditions of Experiments 2 (where the target location varied across trials) and 3 revealed no difference between them. A 2 (experiment) $\times 2$ (SOA: long vs. short) mixed ANOVA showed no main effects $(F \mathbf{s}<1)$ and no interaction effect $\left[F(1,29)=1.387, p>.05, \eta_{\mathrm{p}}^{2}=.04\right]$.

(Manuscript received May 11, 2004; revision accepted for publication January 18,2006 .) 